\title{
Role of ZNF224 in c-Myc repression and imatinib responsiveness in chronic myeloid leukemia
}

\author{
Gaetano Sodaro ${ }^{1}$, Elena Cesaro ${ }^{1}$, Giorgia Montano ${ }^{2}$, Giancarlo Blasio ${ }^{1}$, Federica \\ Fiorentino ${ }^{1}$, Simona Romano ${ }^{1}$, Arnaud Jacquel ${ }^{3}$, Patrick Aurberger ${ }^{3}$ and Paola \\ Costanzo ${ }^{1}$ \\ ${ }^{1}$ Department of Molecular Medicine and Medical Biotechnology, University of Naples, Federico II, Naples 80131, Italy \\ ${ }^{2}$ Department of Haematology and Transfusion Medicine, BioMedical Center, Lund University, Lund 22184, Sweden \\ 3 Université Côte d'Azur, Inserm, Nice 06204, France \\ Correspondence to: Paola Costanzo, email: paola.costanzo@unina.it \\ Keywords: ZNF224; chronic myeloid leukemia; c-Myc; imatinib; AG490 \\ Abbreviations: CML: Chronic myelogenous leukemia; WT1: Wilms Tumor protein 1; TKIs: tyrosine kinase inhibitors; TSS: transcriptions \\ start sites; ChIP: Chromatin immunoprecipitation assays \\ Received: July 26, $2017 \quad$ Accepted: November 17, $2017 \quad$ Published: December 15, 2017 \\ Copyright: Sodaro et al. This is an open-access article distributed under the terms of the Creative Commons Attribution License \\ 3.0 (CC BY 3.0), which permits unrestricted use, distribution, and reproduction in any medium, provided the original author and \\ source are credited.
}

\section{ABSTRACT}

The transcription factor ZNF224 plays a key proapoptotic role in chronic myelogenous leukemia (CML), by modulating Wilms Tumor protein 1 (WT1) dependent apoptotic genes transcription. Recently, we demonstrated that Bcr-Abl signaling represses ZNF224 expression in Bcr-Abl positive CML cell lines and in CML patients. Interestingly, Imatinib and second-generation tyrosine kinase inhibitors specifically increase ZNF224 expression.

On the other hand, Bcr-Abl positively modulates, via JAK2 activation, the expression of the $\mathrm{C}-\mathrm{Myc}$ oncogene, which is required for Bcr-Abl oncogenic transformation in CML. Consequently, JAK2 inhibitors represent promising molecular therapeutic tools in CML.

In this work, we demonstrate that ZNF224 is a novel transcriptional repressor of C-Myc in CML. We also show that ZNF224 induction by Imatinib and AG490, a specific JAK2 inhibitor, is responsible for the transcriptional repression of C-MYC, thus highlighting the crucial role of the ZNF224/C-Myc axis in Imatinib responsiveness.

Interestingly, we also report that ZNF224 is induced by AG490 in Imatinibresistant CML cells, leading to $\mathrm{C}-$ Myc repression and apoptosis induction. These findings suggest that the development of molecular tools able to induce ZNF224 expression could provide promising means to bypass Imatinib resistance in CML.

\section{INTRODUCTION}

The chimeric Bcr-Abl fusion oncoprotein is a product of a reciprocal chromosomal translocation between the long arms of chromosomes 9 and 22 $\mathrm{t}(9 ; 22)(\mathrm{q} 34 ; \mathrm{q} 11)[1]$ and exerts a critical role in chronic myelogenous leukemia (CML) pathogenesis [2-4]. Constitutive tyrosine kinase activity of Bcr-Abl causes the activation of a multitude of signaling pathways, including Jak/STAT [5], PI3K/Akt [6, 7], Ras [8] and NF$\mathrm{kB}[9]$, which eventually lead to the induction of several oncogenic transcription factors, important for sustaining cellular transformation in CML.
c-Myc is one of the oncogenic transcription factors induced by Bcr-Abl. It plays a central role in the regulation of proliferation, differentiation, apoptosis and tumorigenesis of hematopoietic cells and is necessary for Bcr-Abl oncogenic transformation in CML [10]. Consistently, the inhibition of Bcr-Abl tyrosine kinase activity by Imatinib strongly reduces c-Myc expression and hematopoietic tumoral features of CML cells. Importantly, c-Myc reduction represents a key step for Imatinib induced cell death in CML; indeed, elevated c-Myc levels are found during CML blast crisis phase and correlate with poor response to Imatinib [11-13]. 
The induction of c-Myc by Bcr-Abl occurs mainly via JAK2 activation, which positively regulates c-Myc protein and mRNA levels, even though the mechanisms involved in c-Myc transcriptional regulation are still largely unknown [14-17].

In agreement with the JAK2 role in mediating $\mathrm{Bcr}-\mathrm{Abl}$ induction of c-Myc, JAK2 kinase inhibitors, such as AG490, strongly reduce c-Myc expression in CML and induce apoptosis $[14,16]$, thus indicating JAK2 pathway as an important therapeutic target to overcome Imatinib resistance in CML, a crucial issue in clinical practice [17-19].

The Kruppel-like zinc-finger protein ZNF224 is a transcriptional repressor, which has been recently proposed to play a dual role in carcinogenesis, acting as a tumor suppressor or an oncogene, depending on molecular partners and cellular contest [20,21].

In CML, ZNF224 exerts a pro-apoptotic role, acting as a co-factor of the Wilms tumor protein 1 (WT1) transcription factor. ZNF224 is recruited by WT1 on the promoter of apoptosis-regulating genes and, modulating WT1 dependent transcription, it shifts the balance of antiapoptotic and proapoptotic signals in favor of the latter. Through this mechanism, ZNF224 plays a central role in ara-C-induced apoptosis in CML [22-24]. Moreover, we recently found that $\mathrm{Bcr}-\mathrm{Abl}$ negatively regulates the expression of ZNF224 in CML cells via transcriptional repression; consistently, inhibition of Bcr-Abl tyrosine kinase activity, by Imatinib and second generation tyrosine kinase inhibitors, resulted in the up-regulation of ZNF224 expression [25].

In the present study, we demonstrate that ZNF224 represses c-Myc transcription in CML and coherently hampers c-Myc proliferative network, reducing CML cells proliferation and DNA synthesis. Importantly, we also demonstrate that ZNF224 mediates Imatinib and AG490 dependent down-modulation of c-Myc and apoptosis induction in K562 cells. Furthermore, we provide convincing evidence that ZNF224 induction by AG490 could play a role in overcoming Imatinib resistance in CML cells.

\section{RESULTS}

\section{ZNF224 exerts a transcriptional repression on c-Myc expression}

Our previous findings demonstrated that Bcr-Abl fusion protein negatively regulates the expression of the pro-apoptotic transcription factor ZNF224 in CML and accordingly Bcr-Abl inhibition by Imatinib and secondgeneration tyrosine kinase inhibitors (TKIs) Dasatinib and Nilotinib increase ZNF224 expression [25].

The c-Myc oncogene is a target of Bcr-Abl protein transforming activity; indeed, Bcr-Abl inhibition by Imatinib strongly reduces c-Myc expression [10-13]. Coherently, we observed that ZNF224 induction by
Imatinib well correlated with c-Myc downregulation and cell death induction in K562 CML cells (Figure 1A). Moreover, in silico analysis revealed the existence of three putative ZNF224 binding sites on the c-Myc promoter region, from nucleotides -1237 to +334 , including the two transcriptions start sites (TSS) P1 and P2 (Figure 1B, upper panel). This suggests that c-Myc gene could be a target of ZNF224 transcriptional repression in CML.

To assess whether c-Myc promoter activity was affected by ZNF224 and to investigate the regions of c-Myc promoter involved in this regulation, we introduced three luciferase reporter plasmids containing progressive deletions of the c-Myc promoter (Figure 1B, lower panel) into HEK293 cells in the presence of increasing amounts of a ZNF224 expression vector; as shown in Figure 1C, c-Myc promoter transcriptional activity was progressively decreased by ZNF224 overexpression in all the three deletion mutants, thus indicating that ZNF224 represses c-Myc gene through the binding at the high regulatory $\mathrm{P} 2$ region of the c-Myc promoter, that is included in the DEL-6 construct.

In agreement with the results of luciferase assays, ZNF224 overexpression in HEK293 cells also reduced c-Myc protein levels in a dose-dependent manner and was associated with a decrease in cyclin D1 protein levels, a positive c-Myc target gene (Figure 1D). Consistently, we found that the basal transcriptional activity of DEL-6 construct was higher in K562 CML cells, which express lower levels of endogenous ZNF224, compared to HEK293 cells (Figure 1E).

To confirm ZNF224 binding on the P2 region of the c-Myc promoter, we conducted Chromatin immunoprecipitation assays (ChIP) in HEK293 cells. Chromatin was immunoprecipitated with a ZNF224 antibody and RT-qPCR analysis confirmed that ZNF224 was able to bind the $\mathrm{P} 2$ region of the $\mathrm{c}-\mathrm{Myc}$ promoter (Figure 1F).

\section{ZNF224 binds to a regulatory element in the c-Myc promoter in CML}

To confirm the transcriptional repression exerted by ZNF224 on c-Myc in K562 cells and to identify the ZNF224 binding element within the c-MYC promoter, we performed a site-directed mutagenesis of three nucleotides within the ZNF224 binding consensus on DEL-6 construct, obtaining the mutant DEL-6 MUT (Figure 2A), and compared the effect of ZNF224 on the transcriptional activity of wild-type and mutant c-Myc promoter. For this purpose, K562 cells were transfected with DEL-6 or DEL-6 MUT constructs together with the ZNF224-Flag expression vector and luciferase activity was measured. We observed that ZNF224 overexpression significantly reduced c-Myc DEL-6 promoter activity as expected, while it was not able to repress the luciferase activity of DEL-6 MUT construct (Figure 2B). 
A

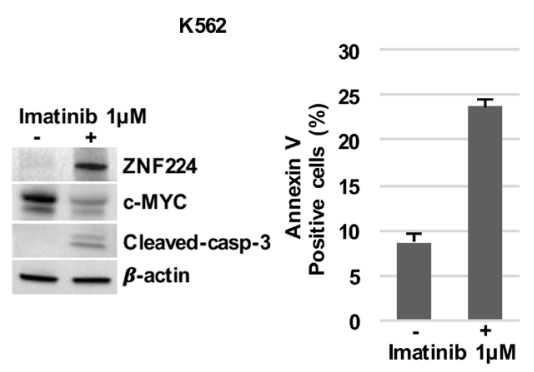

C

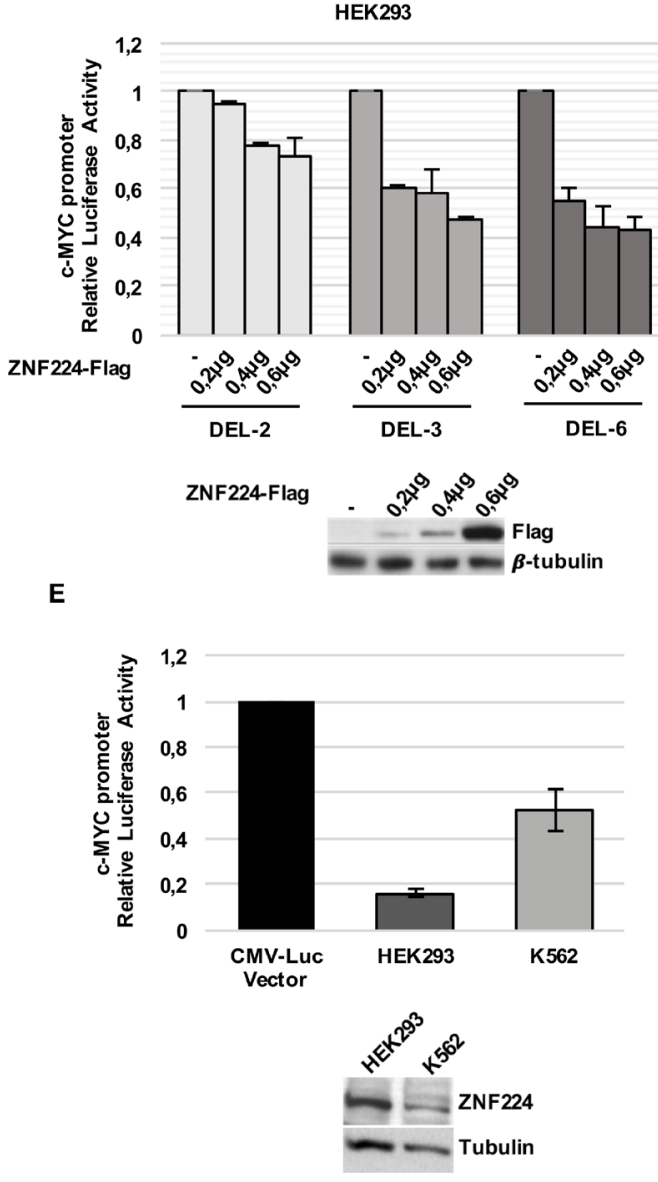

B

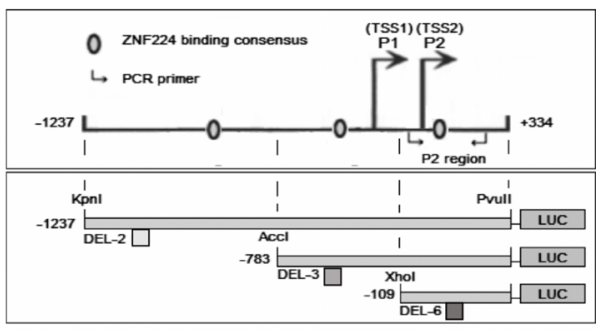

D

HEK293
$\mathbf{F}$

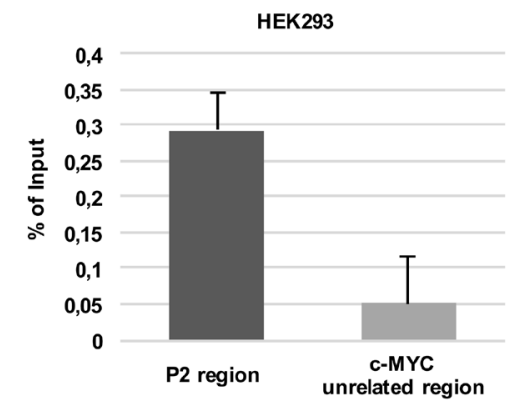

Figure 1: ZNF224 reduces c-Myc expression via a transcriptional mechanism. (A) Western blot analysis of ZNF224, c-Myc and cleaved caspase-3 protein levels in K562 cells treated with Imatinib or vehicle only (DMSO), as control (-), for 48 hours . $\beta$-actin was used as loading control. One representative blot out of two performed is shown (left panel). Cell death was evaluated by annexinV-PE staining followed by flow cytometry. Results represent the means $+/-$ SD of two independent experiments (right panel). (B) Schematic representation of c-Myc promoter region and DEL-2, DEL-3 and DEL-6 deletion constructs. (C) DEL-2, DEL-3 and DEL-6 constructs were transfected into HEK293 cells together with increasing amounts of 3X-Flag ZNF224 or 3X-Flag empty vector as control (-). After $24 \mathrm{~h}$, the promoter activity was determined by normalizing Firefly to Renilla luciferase activity. Error bars represent standard deviations of two independent experiments. Expression of ZNF224-Flag was verified by western blot analysis. $\beta$-tubulin was used as loading control. One representative blot out of three performed is presented. (D) Western blot analysis of ZNF224-Flag, c-Myc and cyclin D1 protein levels in HEK293 cells transfected with increasing amounts of 3X-Flag ZNF224. G3PDH was used as loading control (left panel). Densitometric analysis of c-Myc protein levels. Error bars represent standard deviations of three independent experiments; ${ }^{*} p<0.05$ (right panel). (E) DEL-6 construct was transfected into HEK293 cells and K562 cell. After 24 h, promoter activity was determined by normalizing Firefly to Renilla luciferase activity. DEL-6 activity was compared to CMV Luciferase activity obtained in each cell line. Error bars represent standard deviations of two independent experiments. ZNF224 expression was measured by western blot analysis. $\beta$-tubulin was used as loading control. One representative blot out of two performed is shown. (F) ChIP assay performed with an anti-ZNF224 antibody. Quantitative RT-qPCR analysis was performed using primers flanking the P2 region. A region downstream c-Myc locus was used as negative control (c-Myc unrelated region). Error bars indicate the mean value $+/-$ SD of two independent experiments. 
Furthermore, we transfected DEL-6 or DEL-6 MUT constructs in K562 cells stably knocked-down for ZNF224 (shC3 and shE7 cells) or in shGFP control cells. As shown in Figure 2C, DEL-6 promoter activity was increased by ZNF224 stable knockdown, while the luciferase activity of DEL-6 MUT was not affected by ZNF224 knockdown. Accordingly, we found a substantial reduction in c-Myc protein levels when ZNF224 was overexpressed (Figure 2D), while ZNF224 knocked-down cells showed increased c-Myc protein levels compared to control cells (Figure 2E).

As expected, we observed that the modulation of ZNF224 expression affects c-myc mRNA levels (Supplementary Figure 1).

Apart from its role in regulating cell death and survival, c-Myc oncogene plays a pivotal function in CML oncogenic transformation, mainly by increasing the cell proliferation rate [26-28].

To further support our findings showing ZNF224 repression of c-Myc transcription in $\mathrm{CML}$, we evaluated the proliferation rate in shC3 and shE7 cells. According to c-Myc increased levels, ZNF224 knockdown was associated with an increase in both K562 cell number (Figure 3A) and doubling time (Figure 3B). Furthermore, by BrdU incorporation assays we observed that ZNF224 knockdown was also accompanied by a significant increase in DNA synthesis (Figure 3C). Coherently, a significant decrease in DNA synthesis was observed when ZNF224 was overexpressed (Figure 3D). Finally, we observed that ZNF224 overexpression was accompanied by a decreased proliferative profile, with a reduction of c-Myc, cyclin D1 and PCNA and an increase of p21 and p27 protein levels (Figure 3E).

These data show that ZNF224 exerts a transcriptional repression on c-Myc expression in CML cells and coherently inhibits cell proliferation.

\section{ZNF224 mediates the Imatinib-dependent transcriptional repression of c-Myc in CML and induces cell death in Imatinib-resistant CML cells}

Starting from these data, we decided to investigate whether ZNF224 was involved in Imatinib-mediated transcriptional repression on c-Myc oncogene, which represents a key event in Imatinib responsiveness in CML [11-13].

We firstly examined ZNF224 occupancy on the c-Myc promoter in K562 cells and the effect of Imatinib treatment on this binding by ChIP assays. To this aim, K562 cells were incubated in the absence or presence of Imatinib $1 \mu \mathrm{M}$ for $24 \mathrm{~h}$, then chromatin was immunoprecipitated with a ZNF224 antibody. As shown in Figure 4A, real-time qPCR of immunoprecipitated chromatin revealed a basal ZNF224 occupancy on the $\mathrm{P} 2$ region of the c-Myc promoter that was considerably increased by Imatinib treatment.
Then, we investigated the effect of Imatinib on the activity of the c-Myc promoter constructs DEL-6 and DEL-6 MUT. As shown in Figure 4B, Imatinib treatment reduced DEL-6 promoter activity, while a significantly lower repression was observed on the DEL-6 MUT.

In agreement with ZNF224 induction by Imatinib, these results suggest that ZNF224 binding on c-Myc promoter is required for Imatinib repression of the c-Myc gene.

To further confirm the ZNF224 role in Imatinibdependent repression of c-Myc, shE7 cells were treated with $1 \mu \mathrm{M}$ Imatinib for 48 hours, after which c-Myc expression was evaluated. Interestingly, we found that ZNF224 knockdown impaired Imatinib-dependent downregulation of c-Myc mRNA (Figure 4C) and protein levels (Figure 4D). In addition, as expected, ZNF224 knockdown significantly reduced the cell death induced by Imatinib (Figure 4E). Collectively, these results highlight a mechanism by which ZNF224 contributes to Imatinib responsiveness in CML.

Prompted by these results, we explored the implication of ZNF224/c-MYC axis in Imatinib resistance. At first, we investigated ZNF224 and c-MYC modulation by Imatinib in K562 cells resistant to Imatinib (K562 Ima-R). In these cells, resistance does not involve neither mutations in Bcr-Abl nor increased Bcr-Abl expression [29]. Interestingly, we observed that Imatinib was not able to induce ZNF224 expression and c-Myc reduction, at both mRNA and protein levels (Figure 5A). As expected, no annexin positivity was observed in K562 Ima-R following Imatinib treatment (Supplementary Figure 2).

It is worth noting that forced expression of ZNF224 in these cells reduced c-Myc promoter activity (Figure 5B), resulting in reduced c-Myc protein levels and a significative increase in cell death (Figure 5C).

\section{JAK2 inhibitor AG490 reduces c-Myc expression via ZNF224 induction in CML cells}

JAK2 pathway plays a pivotal role in c-Myc induction by Bcr-Abl [14-17]. Therefore, since ZNF224 is implicated in the c-Myc repression downstream of Bcr$\mathrm{Abl}$, we investigated the involvement of ZNF224 in the transcriptional downregulation of c-Myc by AG490, a specific and potent inhibitor of JAK2.

To investigate these issues, at first we treated K562 cells with AG490 and evaluated ZNF224 and c-Myc expression. As expected, AG490 induced cell death in K562 cells (Figure 6A) and decreased the levels of c-Myc mRNA and protein (Figure 6B and 6C). Interestingly, the reduction of c-Myc was associated with an increase in ZNF224 expression (Figure 6C), thus suggesting the involvement of JAK2 pathway in ZNF224 suppression. Similar results were also obtained in JURL-MK1 CML cells (Supplementary Figure 3). Subsequently, we investigated the effect of AG490 on the activity of the 
c-Myc promoter constructs, DEL-6 and DEL-6 MUT in K562 cells. We observed that AG490 treatment, similarly to Imatinib (Figure 4B), strongly reduced DEL-6 promoter activity, while exerted a lower repression on DEL-6 MUT (Figure 6D), thus indicating that ZNF224 binding on c-Myc promoter is involved in AG490-dependent repression of the c-Myc gene.
Finally, to definitively demonstrate the involvement of ZNF224 in the c-Myc repression by JAK2 inhibitor, we analyzed the AG490 effect on c-Myc expression in shE7 cells. Interestingly, as shown in Figure 6E and 6F, ZNF224 silencing strongly impaired AG490-mediated downregulation of c-Myc expression at mRNA and protein levels. Taken together, these results indicate that ZNF224

A

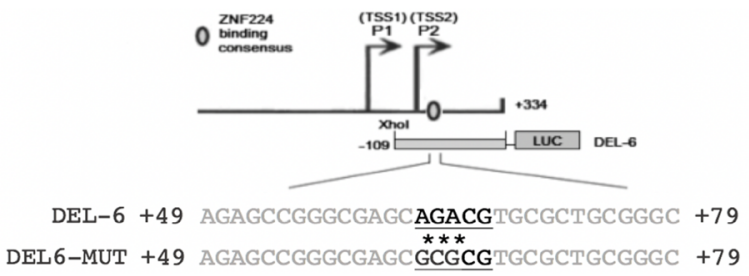

K562

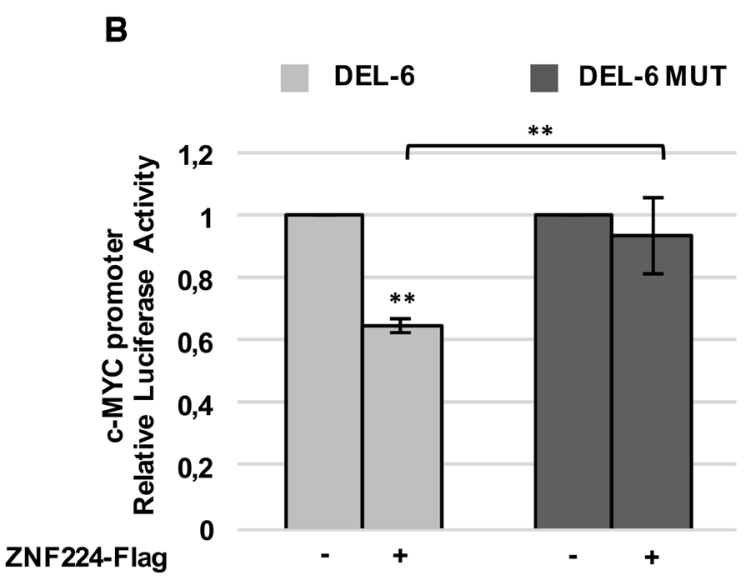

C

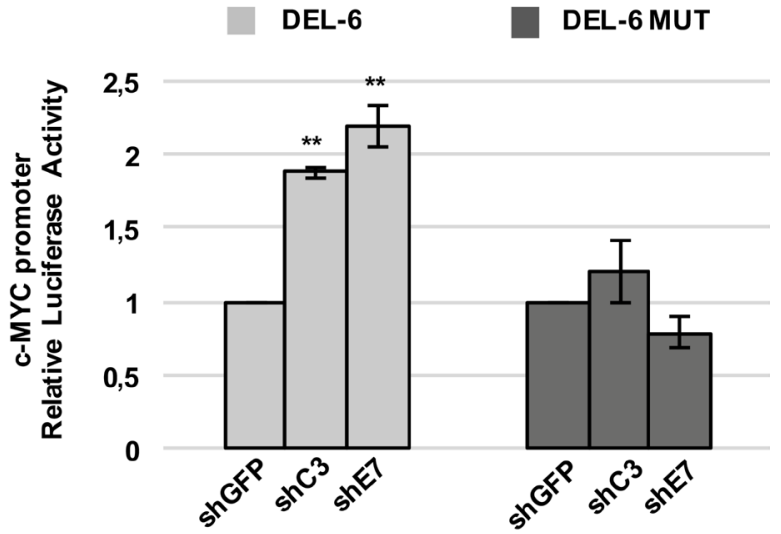

D

$\mathbf{E}$
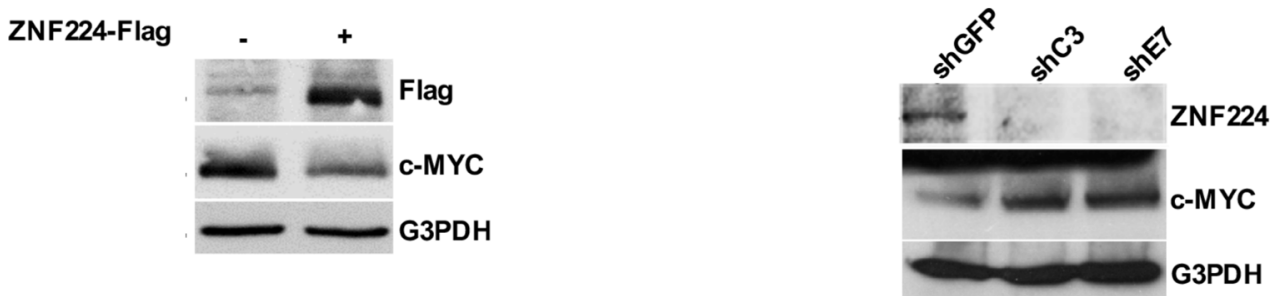

Figure 2: ZNF224 binding on P2 region is crucial for its repression activity on c-Myc promoter in CML. (A) Schematic representation of DEL-6 and DEL-6 MUT constructs. Asterisks (*) indicate mutated bases. (B) K562 cells were transfected with DEL-6 or DEL-6 MUT together with 3X-Flag ZNF224 or 3X-Flag empty vector as control (-). After $48 \mathrm{~h}$, promoter activity was determined by normalizing Firefly to renilla luciferase activity. Error bars represent standard deviations of three independent experiments; ${ }^{* *} p<0.005$. (C) shC3, shE7 and shGFP cells were transfected with DEL-6 or DEL-6 MUT. After 24 h, the Firefly luciferase activity was measured and normalized to Renilla luciferase activity. Error bars represent standard deviations of three independent experiments; ${ }^{* *} p<0.005$. (D) Western blot analysis of ZNF224-Flag and c-Myc protein levels in K562 transfected with 3X-Flag ZNF224 or 3X-Flag empty vector as control (-). G3PDH was used as loading control. (E) Western blot analysis of ZNF224 and c-Myc protein levels in shC3, shE7 and shGFP cells. G3PDH was used as loading control. 
induction mediates, at least in part, AG490 transcriptional repression on c-Myc oncogene in CML cells.

\section{AG490 induces ZNF224 expression and cell death in Imatinib-resistant CML cells}

Subsequently, we evaluated the effect of AG490 on cell death and ZNF224/c-Myc axis in Imatinib-resistant K562 cells. We first observed that AG490 induces cell death (Figure 7A) and caspase activation (Figure 7B) in K562 Ima-R and similar effects were also found in JURL-MK1 Imatinib-resistant cells (Supplementary Figure 4) [30].
Interestingly, we also observed that the induction of apoptosis in K562 Ima-R cells treated with AG490 was associated with ZNF224 induction and c-MYC reduction (Figure $7 \mathrm{C}$ ). Similar results were obtained in K562 Nilotinib-resistant cells (K562 Nilo-R) [31], in which AG490 treatment was able to induce apoptosis, an increase of ZNF224 expression and suppression of c-Myc expression (Supplementary Figure 5).

Furthermore, coherently with the role of ZNF224 in repressing c-Myc and inducing cell death in Imatinib-resistant K562 cells, we demonstrated that ZNF224 silencing, with two different siRNAs (siRNA ZNF224 \#1 and siRNA ZNF224 \#2),
A

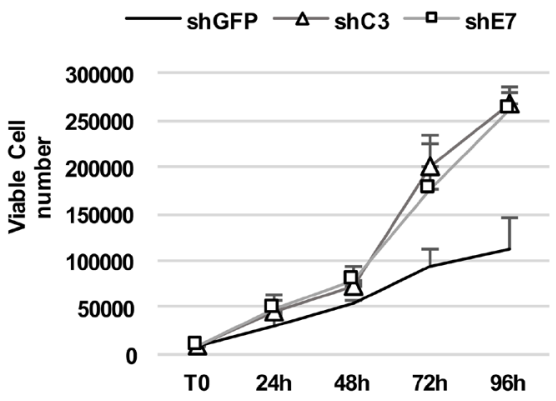

K562

B

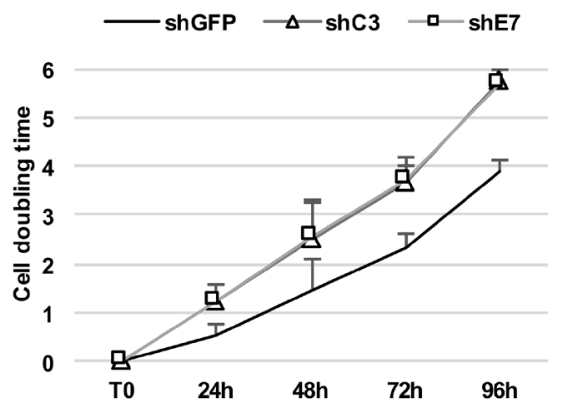

C
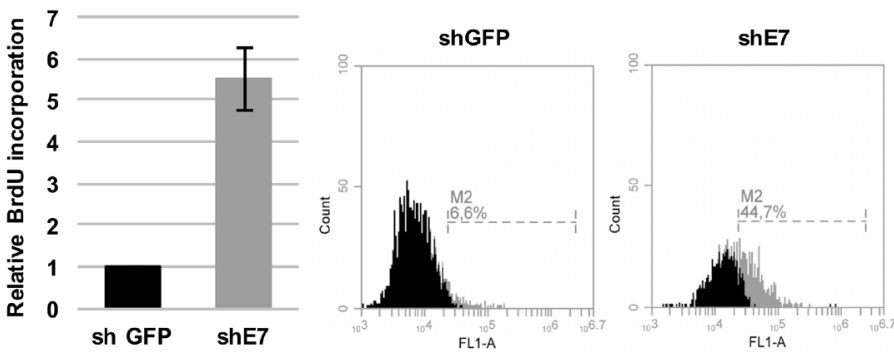

$\mathbf{E}$

D
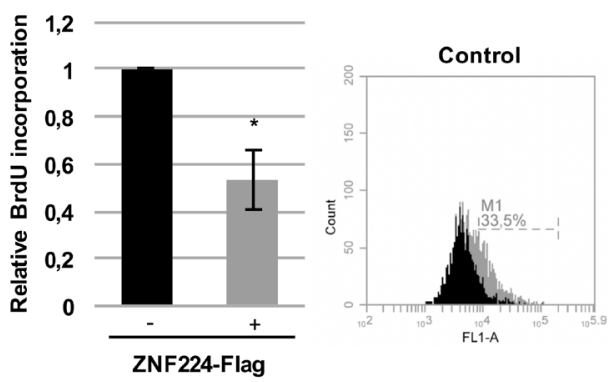

ZNF224 over-expression
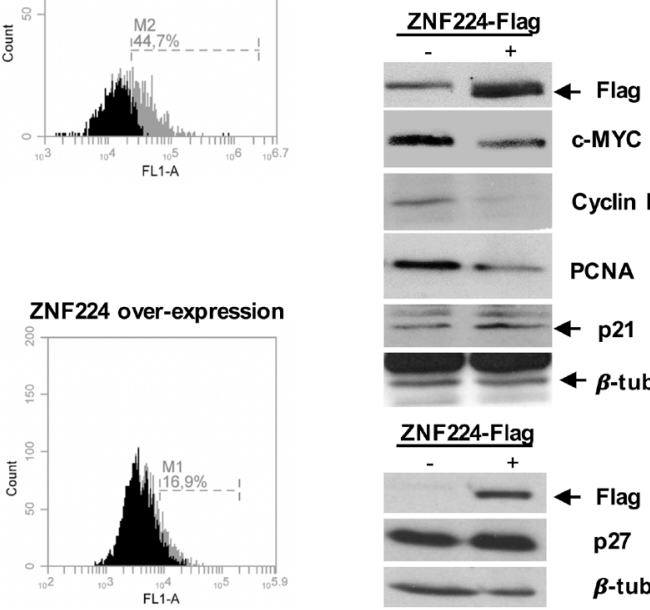

Cyclin D1
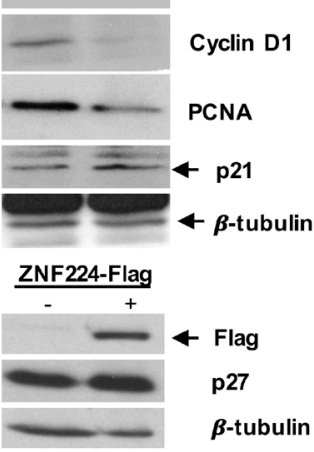

Figure 3: ZNF224 hampers CML cells proliferation. (A) Proliferation rate of shC3, shE7 and shGFP cells evaluated by cell counting. Error bars represent standard deviations of three independent experiments. (B) Proliferation rate evaluated by cell doubling time. Error bars represent standard deviations of two independent experiments. (C) Relative BrdU incorporation in shE7 cells compared to shGFP cells. Error bars represent standard deviations of two independent experiments. Percentage of BrdU incorporation of one representative plot out of two is presented. (D) Relative BrdU incorporation in K562 cells transiently transfected with 3X-Flag ZNF224 expression vector compared to K562 cells transfected with 3X-Flag empty vector, used as control (-). Error bars represent standard deviations of three independent experiments. ${ }^{*}<0.05$. (E) ZNF224-Flag, c-Myc, cyclin D1, PCNA, p21 and p27 levels were analyzed by western blot. Arrows indicate specific bands. $\beta$-tubulin was used as loading control. One representative blot out of two performed is presented. 
A

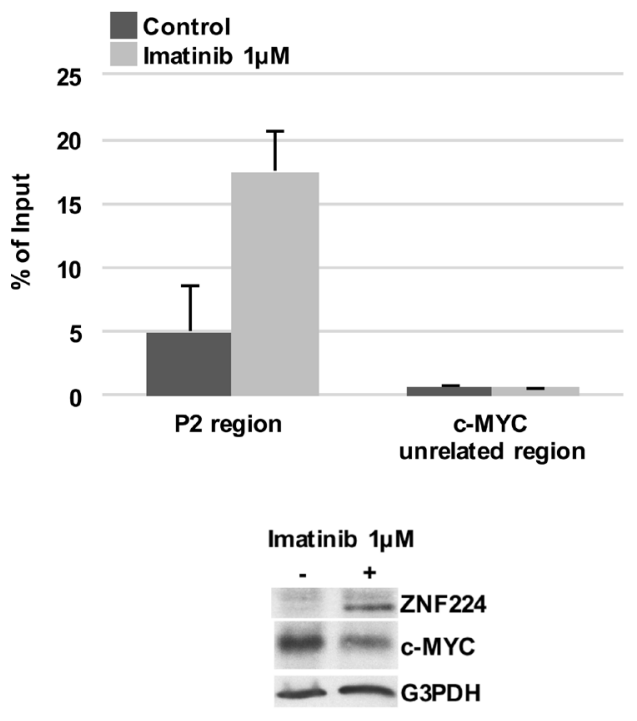

C

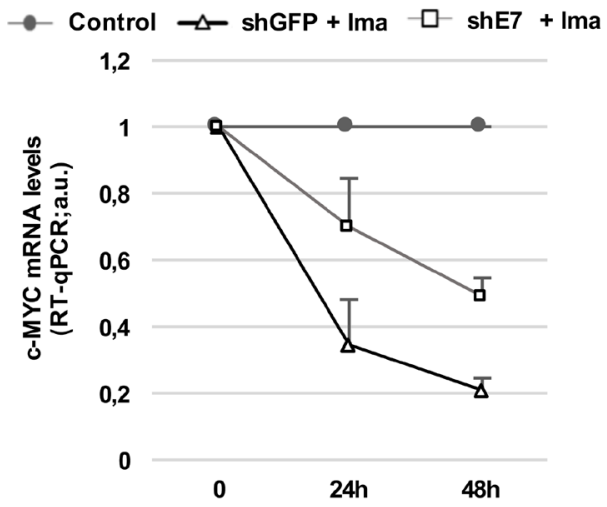

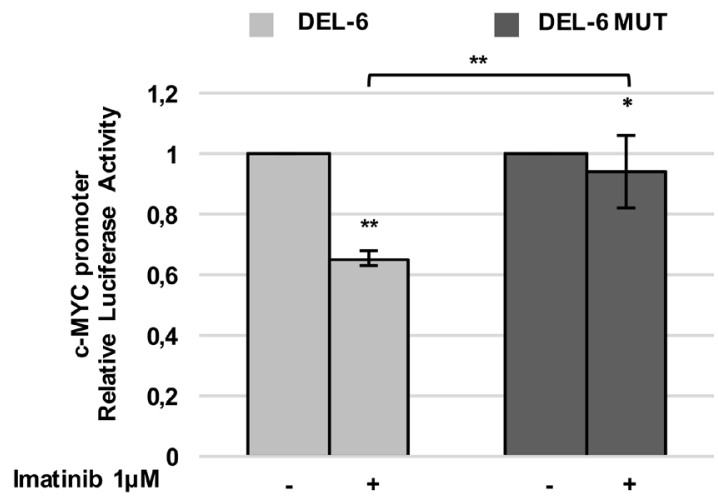

D

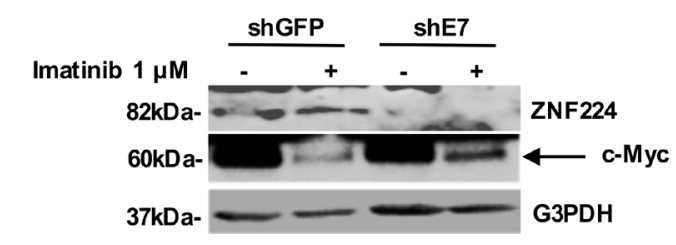

$E$

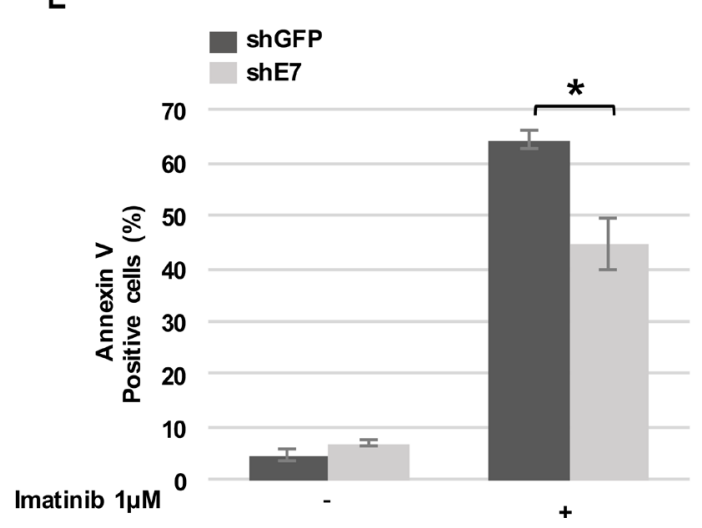

Figure 4: ZNF224 mediates the Imatinib-dependent transcriptional repression on c-Myc. (A) ChIP assay performed with an anti-ZNF224 antibody in K562 cells treated with Imatinib or vehicle only (DMSO) as control for $24 \mathrm{~h}$. Quantitative RT-qPCR analysis was performed using primers covering the $\mathrm{P} 2$ region. A c-Myc unrelated region was used as negative control. Error bars indicate the mean value +/- SD of two independent experiments (upper panel). ZNF224 and c-Myc protein levels were analyzed by western blot. G3PDH was used as loading control. One representative blot out of two performed is shown (lower panel). (B) K562 cells were transfected with DEL-6 or DEL-6-MUT constructs and after 24 hours treated with Imatinib. Luciferase activity was determined 24 hours later and promoter activity was normalized to Renilla luciferase activity. Error bars represent standard deviations of two independent experiments. ${ }^{*} p<0.05$; ${ }^{* *} p<0.005$. (C) shE7 and shGFP cells were exposed to Imatinib or vehicle only (DMSO) for 48 hours. c-Myc mRNA levels were measured by RT-qPCR. Relative amounts of c-Myc mRNA levels in shE7 and shGFP cells treated with Imatinib were compared to those in shE7 and shGFP cells treated with DMSO (control). Error bars represent standard deviations of two independent experiments. (D) ZNF224 and c-Myc protein levels were measured by western blot analysis. Arrow indicates specific band. G3PDH was used as loading control. One representative blot out of two is presented. (E) Cell death was determined by annexin V staining followed by flow cytometry. Error bars represent standard deviations of three independent experiments. ${ }^{*} p<0.05$. 
increased c-Myc expression and significantly impaired AG490 induced cell death of K562 Ima-R cells (Figure 7D)

\section{DISCUSSION}

Bcr-Abl fusion oncoprotein drives the oncogenic transformation in chronic myelogenous leukemia [2-4] by mainly activating oncogenic pathways [5-9], eventually resulting in the induction of several transcription factors, which strongly sustain oncogenic processes in CML. In this context, the c-Myc transcription factor is necessary for the transforming activity of Bcr-Abl [10].
Bcr-Abl positively regulates c-Myc expression in CML [16]. Consistently, inhibition of Bcr-Abl tyrosine kinase activity by Imatinib, the Tyrosine kinase inhibitor (TKI) used as the frontline drug in CML therapy [32, 33], reduces c-Myc expression and tumoral features of $\mathrm{CML}$ cells. A crucial problem linked to TKIs treatment is that the residual leukemic cells accumulate new mutations in Bcr$\mathrm{Abl}$ fusion protein or in other downstream signalling or effector molecules, thus resulting in a refractory response and resistance to TKIs [34]. Several findings showed that elevated c-Myc expression is found in CML blast crisis and correlated with poor response to Imatinib [11]. On the

\section{K562 Ima-R}

A

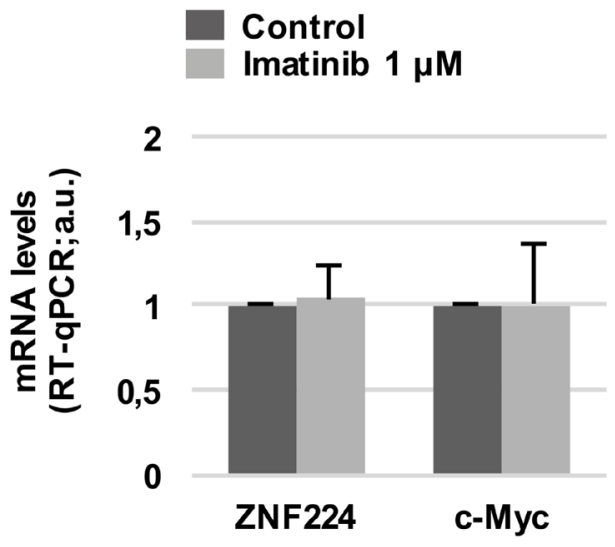

C

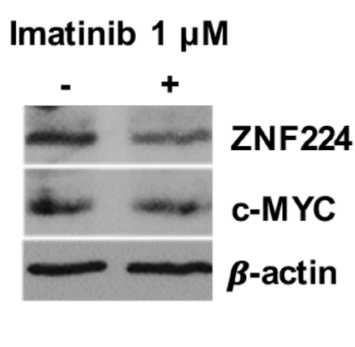

B

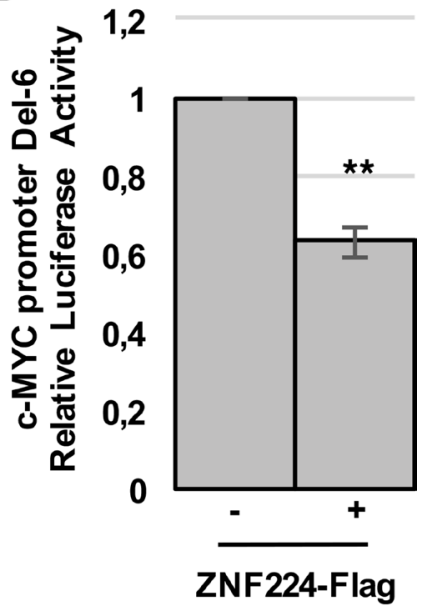

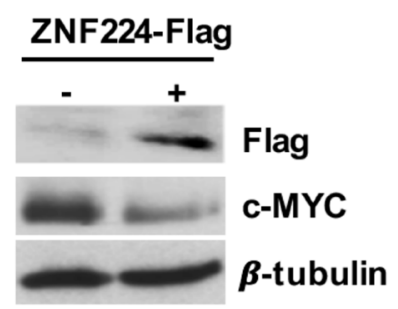

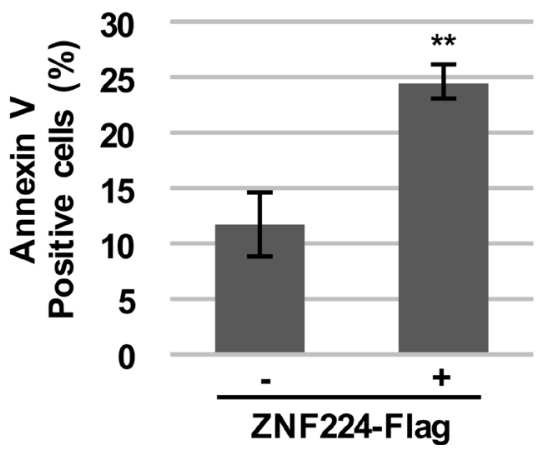

Figure 5: ZNF224 overexpression reduces c-Myc and induces cell death in K562 Ima-R cells. (A) K562 Ima-R cells were exposed to Imatinib or vehicle only (DMSO) as control (-) for 48 hours. ZNF224 and c-Myc mRNA levels were measured by RT-qPCR. Error bars represent standard deviations of three independent experiments (left panel). ZNF224 and c-Myc protein levels were measured by western blot analysis. $\beta$-actin was used as loading control. One representative blot out of two is presented (right panel). (B) K562 Ima-R cells were co-transfected with DEL-6 and 3X-Flag ZNF224 or 3X-Flag empty vector as control (-). After 48 h, promoter activity was determined by normalizing Firefly to Renilla luciferase activity. Error bars represent standard deviations of three independent experiments. ${ }^{* *} p<0.005$. (C) K562 Ima-R cells were transfected with 3X-Flag ZNF224 or 3X-Flag empty vector as control (-). c-Myc protein levels were measured by western blot analysis. $\beta$-tubulin was used as loading control. One representative blot out of two is presented (left panel). Cell death was determined by annexin V staining followed by flow cytometry. Error bars represent standard deviations of three independent experiments. ${ }^{* *} p<0.005$. 
other hand, c-Myc decreased expression represents a key step for Imatinib sensitivity in CML cells $[12,13]$.

We previously showed that the Kruppel-like zinc-finger protein ZNF224 plays a crucial role in ara$\mathrm{C}$-induced apoptosis of CML cells, acting as a WT1 transcriptional cofactor [22-24]. Most recently, we demonstrated that ZNF224 expression is down-regulated both in BCR-ABL positive cell lines and in primary CML samples. We also showed that ZNF224 gene expression is negatively regulated by $\mathrm{Bcr}-\mathrm{Abl}$ oncoprotein via transcriptional repression. In agreement with these findings, we demonstrated that treatment of CML cells with Bcr-Abl inhibitors, such as Imatinib and second generation TKIs increases ZNF224 expression [25].

In this work, we report that ZNF224 binds c-Myc promoter and exerts a transcriptional repression on c-Myc gene in CML, independently of WT1 interaction. In fact, we show that ZNF224 is able to downmodulate c-Myc expression via a transcriptional mechanism in K562 cells, which express high endogenus levels of WT1, as well as in HEK293 cells, which do not express endogenous WT1. Thus, these findings identify the suppression of

\section{K562}

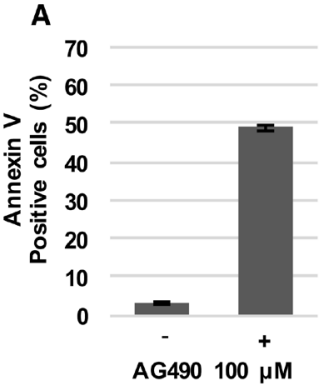

D
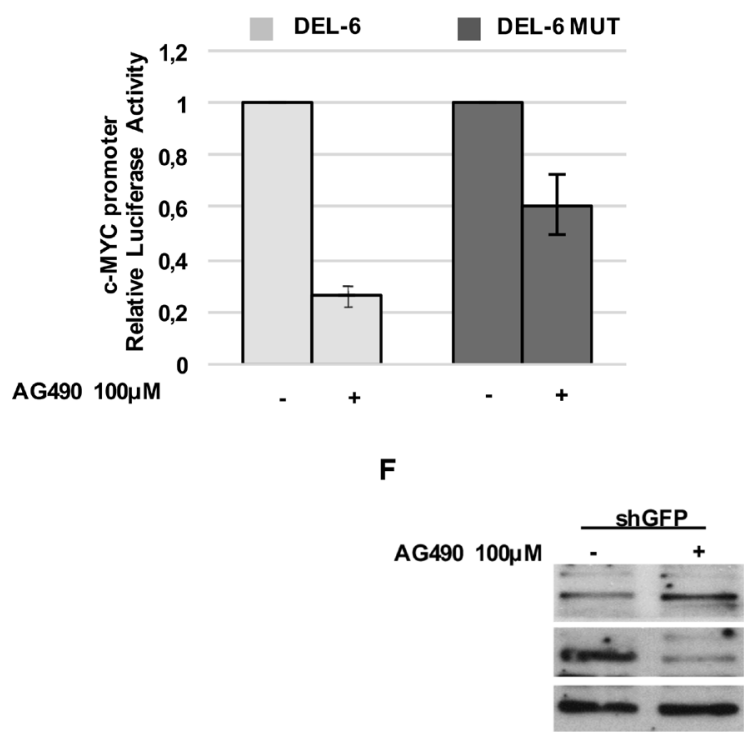

C
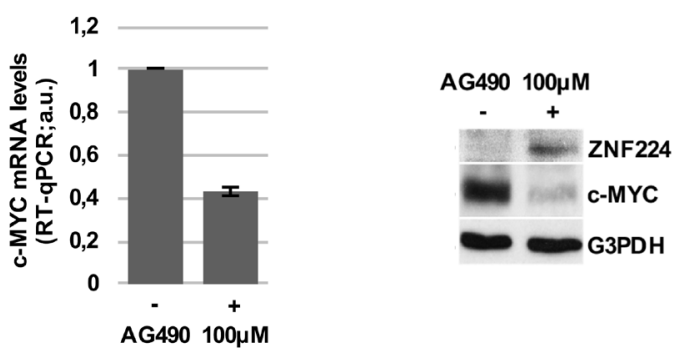

E
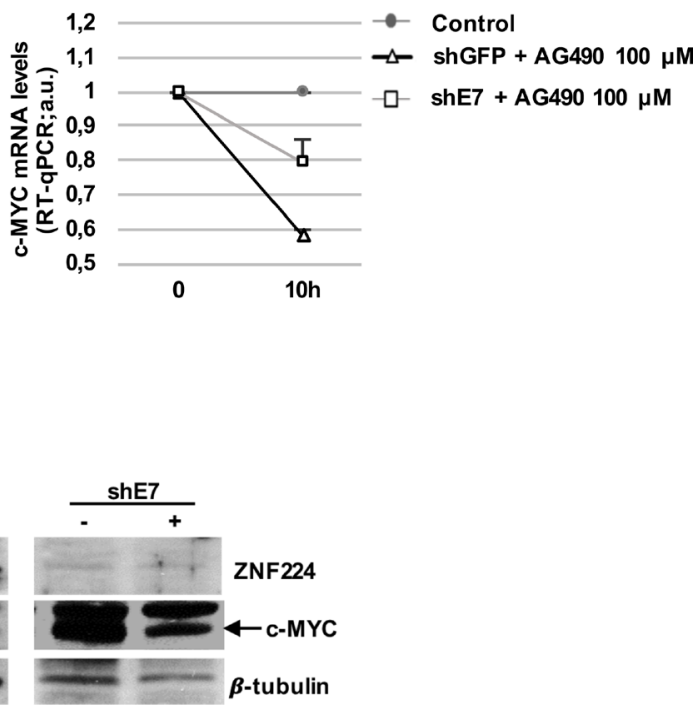

Figure 6: ZNF224 mediates AG490-dependent transcriptional repression on c-Myc. (A) K562 cells were treated with AG490 for $24 \mathrm{~h}$ or vehicle only (DMSO) as control (-). Cell death was evaluated by annexin V staining followed by flow cytometry. Results represent the means +/- SD of two independent experiments. (B) K562 cells were treated with AG490 for 10 hours or vehicle only (DMSO) as control (-). c-Myc mRNA levels were measured by RT-qPCR. Error bars represent standard deviations of two independent experiments. (C) ZNF224 and c-Myc protein levels were measured by western blot analysis. G3PDH was used as loading control. One representative blot out of two performed is shown. (D) K562 cells were transiently transfected with DEL-6 or DEL-6-MUT constructs and treated with AG490 or vehicle only (DMSO) as control (-); after 10 h, luciferase activity was determined by normalizing Firefly to Renilla luciferase activity. Error bars represent standard deviations of two independent experiments. (E) shE7 and shGFP cells were treated with AG490 or vehicle only (DMSO) as control for 10 hours. c-Myc mRNA levels were measured by RT-qPCR. Relative amounts of c-Myc mRNA levels in shE7 and shGFP cells treated with AG490 were compared to those in shE7 and shGFP treated with DMSO (control). Error bars represent standard deviations of two independent experiments. (F) ZNF224 and c-Myc protein levels were measured by western blot analysis. Arrow indicates specific band. $\beta$-tubulin was used as loading control. One representative blot out of two is shown. 
c-Myc expression as a new mechanism by which ZNF224 operates as a tumor suppressor in CML.

Furthermore, we identify a ZNF224-binding element in the c-Myc promoter that is essential for ZNF224 transcriptional repression on c-Myc in CML cells.

However, since WT1 transcription factor also plays a role in c-Myc transcriptional regulation in CML [35], we cannot exclude that ZNF224 could downmodulate c-Myc also by acting as a WT1 transcriptional cofactor and by suppressing WT1-mediated transactivation of c-Myc gene in CML, as already demonstrated for other WT1 target genes $[23,24]$.

We also show that ZNF224 repression on c-Myc in CML results in a decreased proliferation and $\mathrm{c}-\mathrm{Myc}$ proliferative network, leading to a decreased cyclin D1 expression, a positive c-Myc target gene [36], and an increased p21 expression, a negative c-Myc target gene [37-42].

However, it is conceivable that ZNF224 could regulate expression of the above-mentioned genes also by a different mechanism. Indeed, it was recently demonstrated that ZNF224 increases miR-663a transcription, which in turn binds to $3^{\prime}$ UTR of p21 to decrease its expression in MCF-7 breast cancer cell line [43]. Interestingly, miR663 is a tumour suppressor in CML, which may suppress proliferation in part by enhancing cell apoptosis [44].

Importantly, we show that ZNF224 plays a central role in Imatinib-dependent c-Myc repression in CML. In accordance with the key role of c-Myc reduction in Imatinib responsiveness $[12,13]$ and with the already described pro-apoptotic mechanisms driven by ZNF224 in CML cells, ZNF224 knockdown led to an impairment of Imatinib-induced cell death.

However, we cannot rule out that ZNF224 induction also plays a role in the Imatinib-mediated proliferative arrest, as already described for THAP11, another important transcriptional repressor of c-Myc oncogene in CML, downstream Bcr-Abl [45].

We also demonstrate that ZNF224 forced expression in Imatinib-resistant K562 cells [27] is accompanied by

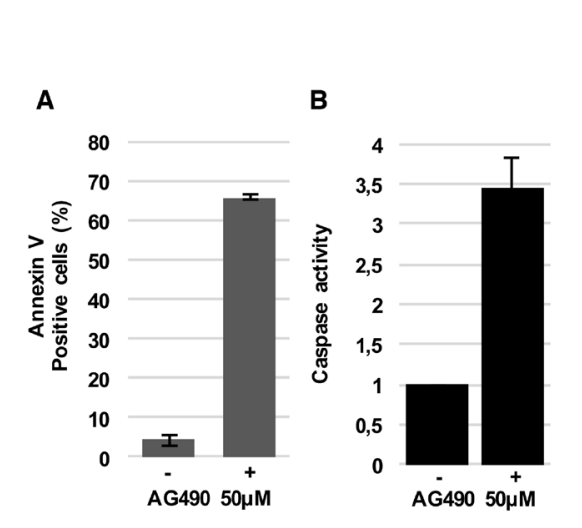

K562 Ima-R
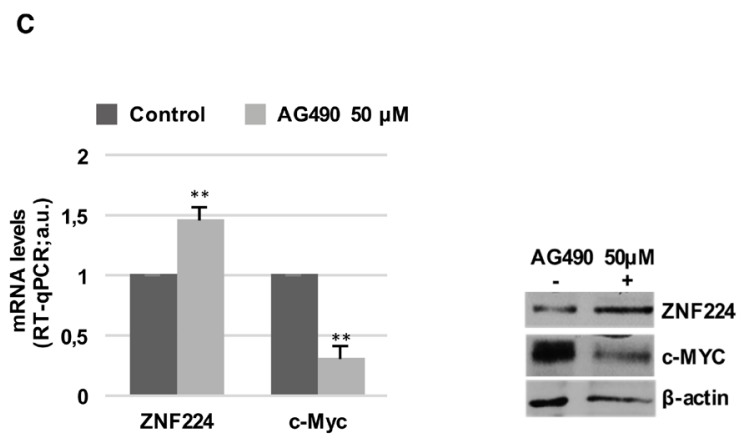

D
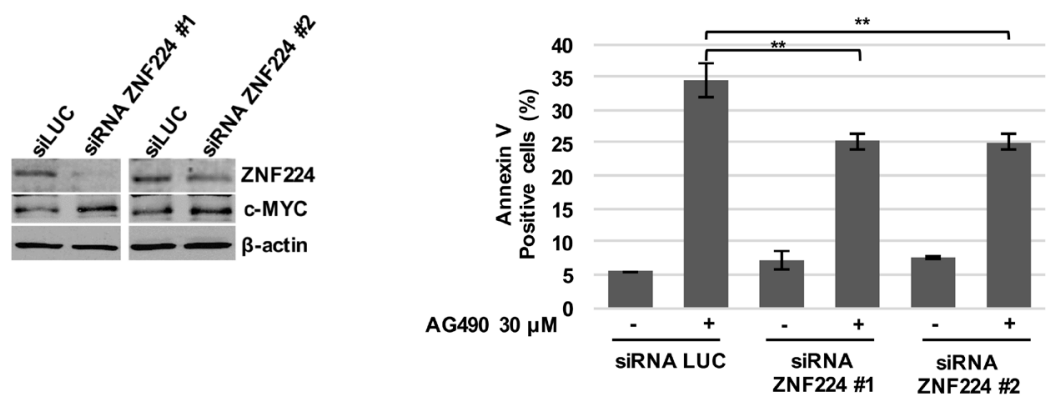

Figure 7: ZNF224 is involved in AG490-induced cell death of K562 Ima-R cells. K562 Ima-R cells were exposed to AG490 or vehicle only (DMSO) as control (-) for 48 hours. (A) Cell death was determined by annexin V staining followed by flow cytometry. Error bars represent standard deviations of three independent experiments. (B) Caspase activity was biochemically measured. (C) ZNF224 and c-Myc mRNA levels were measured by RT-qPCR. Error bars represent standard deviations of three independent experiments. ${ }^{* *} p<0.005$ (left panel). ZNF224 and c-Myc protein levels were measured by western blot analysis. $\beta$-actin was used as loading control. One representative blot out of two is presented (right panel). (D) K562 Ima-R cells were silenced with two different siRNAs versus ZNF224 (siRNA ZNF224\#1 or siRNA ZNF224\#2) or with a control siRNA (siLuc) and after 48 hours were collected or exposed to $30 \mu \mathrm{M}$ AG490 or vehicle only (DMSO) as control (-) for 30 hours. ZNF224 and c-Myc protein levels were evaluated by western blot analysis. $\beta$-actin was used as loading control. One representative blot out of two is presented (left panel). Cell death was determined by annexin V staining followed by flow cytometry. Error bars represent standard deviations of three independent experiments. ${ }^{* *} p<0.005$, (right panel). 
c-Myc reduction and cell death induction. Altogether, these results highlight the role of ZNF224 in Imatinib responsiveness and suggest that its induction could contribute to circumvent Imatinib resistance in CML.

It has been previously demonstrated by Xie et al. [16] that Bcr-Abl-mediated induction of c-Myc expression is dependent on activated JAK2 tyrosine kinase, that plays a key role in the stabilization of c-Myc protein and in the induction of c-Myc mRNA transcription in CML, although the molecular mechanisms of this induction have not been clarified.

Consistently, JAK2 kinase inhibitors, such as AG490, strongly reduce c-Myc expression in CML cells and induce apoptosis $[14,16]$, thus representing promising molecular tools to bypass Imatinib resistance in CML [17-19].

By exploiting the newly discovered link between ZNF224 and c-Myc downstream of Bcr-Abl in CML, we show that ZNF224 expression is induced by AG490 in both sensitive and imatinib-resistant K562 cells. Interestingly, we also demonstrated that AG490 is able to induce apoptosis at least in part via ZNF224 induction and consequent c-Myc repression. These findings strongly suggest that the induction of ZNF224 expression, by targeting signaling pathways downstream of Bcr-Abl, may be exploited as basis for the development of new therapeutic approach in imatinib-resistant CML.

\section{MATERIALS AND METHODS}

\section{Cell lines and reagents}

HEK293T human cell line was cultured in Dulbecco's modified Eagle's medium (Sigma-Aldrich, St Louis, MO, USA) supplemented with $10 \%$ fetal calf serum and $100 \mu \mathrm{g} / \mathrm{ml}$ streptomycin-penicillin mix (SigmaAldrich) at $37^{\circ} \mathrm{C}$ in 5\% CO2. K562 and JURL-MK1 human cell lines were cultured in RPMI 1640 (SigmaAldrich) supplemented with $10 \%$ fetal calf serum and $100 \mu \mathrm{g} / \mathrm{ml}$ penicillin-streptomycin mix (Sigma-Aldrich) at $37^{\circ} \mathrm{C}$ in $5 \% \mathrm{CO} 2 . \mathrm{K} 562$ and JURL-MK1 cells were treated with $1 \mu \mathrm{M}$ Imatinib (Novartis Pharma, Basel, Switzerland), $20 \mathrm{nM}$ of Nilotinib (Novartis Pharma), 10, 30, 50 or $100 \mu \mathrm{M}$ AG490 (Sigma-Aldrich), 500ng/ml Puromycin (Sigma-Aldrich). K562 Ima-R clones were established and described in [29]. K562 Nilo-R clones were established as described in [31]. JURL-MK1 Ima-R clones were established as described in [30].

\section{RNA isolation, reverse transcription and real- time qPCR}

Total RNA was isolated using the Quick-RNATM MiniPrep Plus (Zymo research, Irvine, CA, USA) according to the manufacturer's protocol. $1 \mu \mathrm{g}$ of RNA was reverse-transcribed using the iScript Reverse Transcription Supermix for RT-qPCR (Bio-Rad, Berkeley, CA, USA), as recommended by the manufacturer. Real-time PCR was carried out in a Real-Time CFX 69 System (Bio-Rad) using the Master Mix SYBR Green (Bio-Rad). For RTqPCR analysis of mRNA levels, we used specific primers for ZNF224 (Fw 5'-GGGCTGTCTTGGCACAATTC-3'; Rev 5'-TTGCCTCCTTGAACGTGGTC-3') and c-Myc (Fw 5'-ACTCTGAGGAGGAACAAGAA-3'; Rev 5'- TG GAGACGTGGCACCTCTT-3'). Abl (Fw 5'-GATGTAG TTGCTTGGGACCCA-3'; Rev 5'- TGGAGATAACACT CTAAGCATACT-3') and b2 microglobulin (Fw 5'- CCGT GGCCTTAGCTGTGCT-3'; Rev 5'- TCGGATGGATGA AACCCAGA-3') specific primers were used as control. The relative quantification in gene expression was determined using the $\Delta \Delta \mathrm{CT}$ method.

\section{Cell lysates and western blot assays}

Total cell lysates were prepared by homogenization in modified RIPA buffer as previously described [46]. Western blot membranes were incubated with the following antibodies: anti-ZNF224 (rabbit polyclonal, T3) [47] diluted 1:300 in Super-Block Blocking Buffer (Thermo Fisher Scientific, Waltham, MA, USA), anti-cMyc, anti-Cyclin D1, anti-p21, anti-p27 and anti-PCNA (Santa Cruz Biotechnology, CA, USA) diluted 1:500, anti-GAPDH (Santa Cruz Biotechnology) diluted 1:1000, anti- $\beta$-actin (Sigma-Aldrich) diluted 1:1000, anti-Flag and anti- $\beta$-Tubulin (Upstate, Lake Placid, NY) diluted 1:1000, anti-caspase 3 cleaved (Santa Cruz Biotechnology). Signals were detected with ImmunoCruz Western Blotting Luminol Reagent (Santa Cruz Biotechnology).

The band intensity of c-Myc was quantified by densitometry, using imageJ software. The expression levels of c-Myc in cells transfected with $0,5 \mu \mathrm{g}$ of $3 \mathrm{X}$-Flag ZNF224 was arbitrarily set to 1 .

\section{Transient and stable transfection}

HEK293 cells were transiently transfected using Metafectene (Biontex, Munchen, Germany) with either $0,5 \mu \mathrm{g}$ or $1 \mu \mathrm{g}$ or $2 \mu \mathrm{g}$ of $3 \mathrm{X}$-Flag ZNF224 expression plasmid. As control, $0,5 \mu \mathrm{g}$ or $1 \mu \mathrm{g}$ or $2 \mu \mathrm{g}$ of $3 \mathrm{X}$-Flag empty vector were transfected. K562 cell lines were transiently transfected, using Lipofectamine 2000 (Thermo Fisher), with either 1,5 $\mu \mathrm{g}$ of $3 \mathrm{X}$-Flag ZNF224 expression plasmid or $1,5 \mu \mathrm{g}$ of two different shRNA specific for ZNF224 (shC3 and shE7). As control, 1,5 $\mu \mathrm{g}$ of 3X-Flag empty vector or shRNA specific for GFP were transfected.

To obtain K562 cells stably knocked-down for ZNF224, K562 cells transfected with two different ZNF224 shRNAs (shC3 and shE7) or with an shRNA targeting GFP (shGFP) as control were cultured in RPMI supplemented with $10 \%$ FBS and selected with $500 \mathrm{ng} / \mathrm{mL}$ Puromycin (Sigma-Aldrich) for one week. 
K562 Ima-R cells were transiently transfected, using Lipofectamine RNAiMAX Reagent (Thermo Fisher) with either 90 pmol of two different pool of siRNAs specific for ZNF224: siRNA ZNF224 pool \#1 (ZNF224HSS144559, by Thermo Fisher) or siRNA ZNF224 pool \#2 (ZNF224HSS144560, by Thermo Fisher). As control, 90 pmol of siRNA specific for Luciferase were transfected. $48 \mathrm{~h}$ after transfection, cells were collected or treated.

\section{Luciferase reporter assays}

HEK293 cells were transiently transfected with luciferase reporter plasmids containing the c-Myc promoter (0,2 $\mu \mathrm{g}$ of c-Myc Del-2/Del-3/Del-6 plasmids) and $\mathrm{pRL}-\mathrm{CMV}$ plasmid coding for the renilla luciferase to normalize (1:10 the ratio between renilla and c-Myc construct) using Metafectene (Biontex). c-Myc Del2 and Del-3 plasmids were a gift from Bert Vogelstein (Addgene plasmid \# 16603) [48]. c-Myc Del-6 plasmid was a gift from Joan Massague (Addgene plasmid \# 14969) [48]. HEK293 cells were co-transfected with $0,2 \mu \mathrm{g}, 0,4 \mu \mathrm{g}$ or $0,6 \mu \mathrm{g}$ of $3 \mathrm{X}$-Flag ZNF224 expression plasmid or with $0,2 \mu \mathrm{g}, 0,4 \mu \mathrm{g}, 0,6 \mu \mathrm{g}$ of $3 \mathrm{X}$-Flag empty vector as control $(-)$.

K562 and K562 Ima-R cell lines were transiently transfected with 0,2 $\mu \mathrm{g}$ of c-Myc Del-6 luciferase reporter plasmid and pRL-CMV plasmid to normalize, using Lipofectamine 2000 (Thermo Fisher). K562 and K562 Ima-R cell lines were co-transfected with $1 \mu \mathrm{g}$ of $3 \mathrm{X}-\mathrm{Flag}$ ZNF224 expression plasmid or with $1 \mu \mathrm{g}$ of $3 \mathrm{X}$-Flag empty vector, as control. After 24 or $48 \mathrm{~h}$, luciferase activity was measured in HEK293, K562 or K562 Ima-R cell lines, using the Dual-Luciferase Reporter Assay System (Promega Corporation, WI, USA), according to the manufacturer's instructions.

\section{Chromatin immunoprecipitation assay}

Cross-linked chromatin was prepared from HEK293 or K562 cells and immunoprecipitated with anti-ZNF224 antibody (Santa Cruz Biotechnology), as previously described [49]. Immunoprecipitated DNA was then analyzed by quantitative RT-qPCR using a Master Mix SYBR Green (Bio-Rad) and specific primers for: c-Myc promoter (P2 region) (Fw: 5'-TCGGGGCTTTATCTAACTCG-3'; Rev: 5'-GCTGC TATGGGCAAAGTTTC-3') and Unrelated c-Myc region [Fw 5'-GAAGCGGAAATTGCAGTGAG-3'; Rev:5'AGGGATAGGGTCTTGCTACG-3'). The percentage of DNA immunoprecipitated with anti-ZNF224 antibody was calculated relative to the ChIP input DNA.

\section{Cell counting and annexin $V$ assay}

For cell number determination, K562 cells stably silenced for ZNF224 were plated at a density of $1 \times 10^{4}$ cells/mL in a 24 well plate and viable cells were counted from 1 to 4 days by trypan blue exclusion every 24 hours. For cell doubling time determination, K562 cells stably silenced for ZNF224 were plated at a density of $4 \times 10^{4}$ cells $/ \mathrm{mL}$ in a 12 well plate and viable cells were counted every 24 hours from plating. Cell doubling time was calculated by $\log _{2}\left(n^{\circ}\right.$ counted cells $/ n^{\circ}$ plated cells $)$.

For annexin V staining, $1 \times 10^{5}$ cells were washed twice in cold PBS, then resuspended in cold annexin V-binding buffer ( $5 \mathrm{M} \mathrm{NaCl}, 1 \mathrm{M} \mathrm{CaCl}$, $1 \mathrm{M}$ HEPES buffer/NaOH pH 7.4) and stained with annexin V-APC (BD Biosciences, San Jose, CA, USA). After incubation in the dark on a shaker for $15 \mathrm{~min}$ at $4^{\circ} \mathrm{C}$, cells were analyzed on FACS flow cytometer BD Biosciences Accuri C6 Flow Cytometer (BD Biosciences).

\section{Site-directed mutagenesis of c-Myc promoter reporter construct}

Mutant constructs were generated by the QuikChange $^{\circledR}$ site-directed mutagenesis kit (Stratagene, San Diego, CA, USA) using c-Myc Del-6 (-109 to +334) as DNA template. Mutagenesis was performed in according to the manufacturer's instructions. An oligonucleotide to convert AGA to GCG in c-Myc promoter, was synthesized (5' - GTGGAAGAGCCGGGCGAGCGCGGCTGCGCTG CGGGCGTCC $-3^{\prime} \mathrm{N}$ bp $=40 ; \% \mathrm{GC}=80 ; \% \mathrm{MM}=7.5$; $\mathrm{Tm}=89.925^{\circ} \mathrm{C}$ ). Obtained mutation of the Del- 6 construct was confirmed by DNA sequencing.

\section{BrdU incorporation assay}

Cell proliferation measured with 5-bromo-20deoxy-uridine labelling was performed with a Detection Kit II (Roche Diagnostics Corporation, Indianapolis, IN, USA) following the manufacturer's instructions. Briefly, K562 cells stable silenced for ZNF224 were plated at a density of $3 \times 10^{5}$ cells/ 6 -well plate. To obtain ZNF224 overexpression, $4 \times 10^{5} \mathrm{~K} 562$ cells were transiently transfected with $7 \mu \mathrm{g}$ of $3 \mathrm{X}-\mathrm{Flag}$ ZNF224 expression plasmid or $3 \mathrm{X}$-Flag empty vector for 24 hours, and then $2 \times 10^{5}$ of transfected cells were plated into 6-well plates. K562 cells knocked-down or ovexpressing ZNF224 were incubated in the presence of $10 \mu \mathrm{M}$ BrdU for 3 or 5 hours, then collected, fixed with ethanol and incubated with anti-BrdU monoclonal antibody (Roche). The percentage of BrdU incorporation was measured on FACS flow cytometer (BD Biosciences Accuri C6 Flow Cytometer).

\section{Caspase activity measurement}

K562 cells were lysed in lysis buffer for $30 \mathrm{~min}$ at $4^{\circ} \mathrm{C}$ [50]. The lysates were cleared at $10,000 \mathrm{~g}$ for $15 \mathrm{~min}$ at $4^{\circ} \mathrm{C}$. Each assay was performed using $25 \mu \mathrm{g}$ of protein extract incubated in a 96-well plate with Ac-DEVD-AMC (7-amino-4-methylcoumarin) or Ac-LEHD-AMC (0,2 $\mathrm{mmol} / \mathrm{L}$ ) for various times at $37^{\circ} \mathrm{C}$, as described [50]. 


\section{Statistical analysis}

All data are presented as mean \pm SD. Statistical analysis was performed with Student's $t$-test [two-tailed]. ${ }^{*} p<0.05,{ }^{* *} p<0.005 . P$ value $<0.05$ was defined as statistically significant.

\section{Author contributions}

G.S. designed and performed experiments, analyzed data and wrote the manuscript; E.C designed and analyzed experiments. G.M, G.B, F.F, performed experiments; S.R conducted FACS analysis. A.J supported some experiments on imatinib resistant cell lines. P.A contributed to the experimental design and provided scientific advice. P.C. developed the concept, designed experiments and wrote the manuscript.

\section{ACKNOWLEDGMENTS}

We are grateful to Prof. Michela Grosso, Prof. Fiammetta Romano and Prof. Tommaso Russo (University of Naples, Italy) for helpful suggestions and for critical reading of the manuscript.

\section{CONFLICTS OF INTEREST}

The authors declare no competing financial interests.

\section{REFERENCES}

1. Quintàs-Cardama A, Cortes J. Molecular biology of bcrabl1-positive chronic myeloid leukemia. Blood. 2009; 113:1619-30

2. Shtivelman E, Lifshitz B, Gale RP, Ganaani E. Fused transcript of abl and ber genes in chronic myelogenous leukaemia. Nature. 1985; 315:550-4.

3. Lugo TG, Pendergast AM, Muller AJ, Witte ON. Tyrosine kinase activity and transformation potency of Bcr-Abl oncogene products. Science. 1990; 247:1079-82.

4. Daley GQ, Van Etten RA, Baltimore D. Induction of chronic myelogenous leukemia in mice by the $\mathrm{P} 210 \mathrm{bcr} / \mathrm{abl}$ gene of the Philadelphia chromosome. Science. 1990; 247:824-30.

5. Carlesso N, Frank DA, Griffin JD. Tyrosyl phosphorylation and DNA binding activity of signal transducers and activators of transcription (STAT) proteins in hematopoietic cell lines transformed by Bcr/Abl. J Exp Med. 1996; 183:811-20.

6. Skorski T, Bellacosa A, Nieborowska Skorska M, Majewski M, Martinez R, Choi JK, Trotta R, Wlodarski P, Perrotti D, Chan TO, Wasik MA, Tsichlis PN, Calabretta B. Transformation of hematopoietic cells by BCR/ABL requires activation of a PI-3k/Akt-dependent pathway. EMBO J. 1997; 16:6151-61.
7. Varticovski L, Daley GQ, Jackson P, Baltimore D, Cantley LC. Activation of phosphatidylinositol 3-kinase in cells expressing abl oncogene variants. Mol Cell Biol. 1991; 11:1107-13.

8. Sawyers CL, McLaughlin J, Witte ON. Genetic requirement for Ras in the transformation of fibroblasts and hematopoietic cells by the Bcr-Abl oncogene. J Exp Med. 1995;181:307-13.

9. Reuther JY, Reuther GW, Cortez D, Pendergast AM, Baldwin AS Jr. A requirement for NF-kappaB activation in Bcr-Abl-mediated transformation. Genes Dev. 1998; 12:968-81.

10. Sawyers CL, Callahan W, Witte ON. Dominant negative Myc blocks transformation by ABL oncogenes. Cell. 1992; 70:901-10.

11. Albajar M, Gomez-Casares MT, Llorca J, Mauleon I, Vaque JP. Myc in chronic myeloid leukemia: induction of aberrant DNA synthesis and association with poor response to Imatinib. Mol Cancer Res. 2011; 9:564-576.

12. Gomez-Casares MT, Garcia-Alegria E, Lopez-Jorge CE, Ferrandiz N, Blanco R, Alvarez S, Vaqué JP, Bretones G, Caraballo JM, Sánchez-Bailón P, Delgado MD, Martín-Perez J, Cigudosa JC, et al. Myc antagonizes the differentiation induced by Imatinib in chronic myeloid leukemia cells through downregulation of p27(KIP1). Oncogene. 2013; 32:2239-46.

13. Kawano T, Horiguchi-Yamada J, Iwase S, Akiyama M, Furukawa Y, Kan Y, Yamada H. Depsipeptide enhances Imatinib mesylate-induced apoptosis of Bcr-Abl-positive cells and ectopic expression of cyclin D1, c-Myc or active MEK abrogates this effect. Anticancer Res. 2004; 24:2705-12.

14. Xie S, Wang Y, Liu J, Sun T, Arlinghaus RB. Involvement of Jak2 tyrosine phosphorylation in Bcr-Abl transformation. Oncogene. 2001; 20:6188-95.

15. Miyamoto N, Sugita K, Goi K, Inukai T, Lijima K, Tezuka T, Kojika S, Nakamura M, Kagami K, Nakazawa S. The JAK2 inhibitor AG490 predominantly abrogates the growth of human B-precursor leukemic cells with 11q23 translocation or Philadelphia chromosome. Leukemia. 2001; 15:1758-68.

16. Xie S, Lin H, Sun T, Arlinghaus RB. Jak2 is involved in c-Myc induction by Bcr-Abl. Oncogene. 2002; 21:7137-46.

17. Samanta AK, Lin H, Sun T, Kantarjian H, Arlinghaus RB. Janus kinase 2: a critical target in chronic myelogenous leukemia. Cancer Res. 2006; 66:6468-72.

18. Samanta AK, Chakraborty SN, Wang Y, Kantarjian H, Sun X, Hood J, Perrotti D, Arlinghaus RB. Jak2 inhibition deactivates Lyn kinase through the SET-PP2A-SHP1 pathway, causing apoptosis in drug-resistant cells from chronic myelogenous leukemia patients. Oncogene. 2009; 28:1669-81.

19. Samanta A, Perazzona B, Chakraborty S, Sun X, Modi $\mathrm{H}$, Bhatia R, Priebe W, Arlinghaus RB. Janus kinase 2 
regulates Bcr-Abl signaling in chronic myeloid leukemia. Leukemia. 2011; 25:463-72.

20. Cesaro E, Sodaro G, Montano G, Grosso M, Lupo A, Costanzo P. Complex Role of the ZNF224 Transcription Factor in Cancer. The Adv Protein Chem Struct Biol. 2017; 107:191-222.

21. Busiello T, Ciano M, Romano S, Sodaro G, Garofalo O, Bruzzese D, Simeone L, Chiurazzi F, Romano MF, Costanzo P, Cesaro E. Role of ZNF224 in cell growth and chemoresistance of chronic lymphocitic leukemia. Hum Mol Genet. 2017; 26:344-53.

22. Florio F, Cesaro E, Montano G, Izzo P, Miles C, Costanzo $\mathrm{P}$. Biochemical and functional interaction between ZNF224 and ZNF255, two members of the Kruppel-like zinc-finger protein family and WT1 protein isoforms. Hum Mol Genet. 2010; 19:3544-58.

23. Montano G, Cesaro E, Fattore L, Vidovic K, Palladino C, Crescitelli R, Izzo P, Turco MC, Costanzo P. Role of WT1-ZNF224 interaction in the expression of apoptosisregulating genes. Hum Mol Genet. 2013; 22:1771-82.

24. Montano G, Ullmark T, Jernmark-Nilsson H, Sodaro G, Drott K, Costanzo P, Vidovic K, Gullberg U. The hematopoietic tumor suppressor interferon regulatory factor 8 (IRF8) is upregulated by the antimetabolite cytarabine in leukemic cells involving the zinc finger protein ZNF224, acting as a cofactor of the Wilms' tumor gene 1 (WT1) protein. Leuk Res. 2016; 40:60-7.

25. Montano G, Vidovic K, Palladino C, Cesaro E, Sodaro G, Quintarelli C, De Angelis B, Errichiello S, Pane F, Izzo P, Grosso M, Gullberg U, Costanzo P. WT1-mediated repression of the proapoptotic transcription factor ZNF224 is triggered by the Bcr-Abl oncogene. Oncotarget. 2015; 6:28223-37. https://doi.org/10.18632/oncotarget.4950.

26. Hoffman B, Liebermann DA. Apoptotic signaling by c-myc. Oncogene. 2008; 27:6462-72.

27. Askew DS, Ashmun RA, Simmons BC, Cleaveland JL. Constitutive c-myc expression in an IL-3-dependent myeloid cell line suppresses cell cycle arrest and accelerates apoptosis. Oncogene. 1991; 6:1915-22.

28. Bretones G, Delgado MD, León J. Myc and cell cycle control. Biochim Biophys Acta. 2015;1849:506-16

29. Grosso S, Puissant A, Dufies M, Colosetti P, Jacquel A, Lebrigand K, Barbry P, Deckert M, Cassuto JP, Mari B, Auberger P. Gene expression profiling of Imatinib and PD166326-resistant CML cell lines identifies Fyn as a gene associated with resistance to Bcr-Abl inhibitors. Mol Cancer Ther. 2009; 8:1924-33.

30. Fenouille N, Puissant A, Dufies M, Robert G, Jacquel A, Ohanna M, Deckert M, Pasquet JM, Mahon FX, Cassuto JP, Raynaud S, Tartare-Deckert S, Auberger P. Persistent Activation of the Fyn/ERK Kinase Signaling Axis Mediates Imatinib Resistance in Chronic Myelogenous Leukemia Cells through Upregulation of Intracellular SPARC. Cancer Res. 2010; 70:9659-70.
31. Mahon FX, Hayette S, Lagarde V, Belloc F, Turcq B, Nicolini F, Belanger C, Manley PW, Leroy C, Etienne $\mathrm{G}$, Roche S, and Pasquet JM. Evidence that resistance to nilotinib may be due to Bcr-Abl, Pgp, or Src kinase overexpression. Cancer Research. 2008; 68:9809-16.

32. Kantarjian HM, Cortes JE, O'Brien S, Giles F, GarciaManero G, Faderl S, Thomas D, Jeha S, Rios MB, Letvak L, Bochinski K, Arlinghaus R, Talpaz M. Imatinib mesylate therapy in newly diagnosed patients with Philadelphia chromosome-positive chronic myelogenous leukemia: high incidence of early complete and major cytogenetic responses. Blood. 2003; 101:97-100.

33. Chu S, Holtz M, Gupta M, Bhatia R. BCR/ABL kinase inhibition by imatinib mesylate enhances MAP kinase activity in chronic myelogenous leukemia CD34+ cells. Blood. 2004; 103:3167-74.

34. Mahon FX, Deininger MW, Schultheis B, Chabrol J, Reiffers J, Goldman JM, Melo JV. Selection and characterization of Bcr-Abl positive cell lines with differential sensitivity to the tyrosine kinase inhibitor STI571: diverse mechanisms of resistance. Blood. 2000; 96:1070-79.

35. Han Y, San-Marina S, Liu J, Minden MD. Transcriptional activation of c-Myc proto-oncogene by WT1 protein. Oncogene. 2004; 23:6933-41.

36. Daksis JI, Lu RY, Facchini LM, Marhin WW, Penn LJ. Myc induces cyclin D1 expression in the absence of de novo protein synthesis and links mitogen-stimulated signal transduction to the cell cycle. Oncogene. 1994; 9:3635-45.

37. Gartel AL, Shchors K. Mechanisms of c-Myc-mediated transcriptional repression of growth arrest genes. Exp Cell Res. 2003; 283:17-21.

38. Claassen GF, Hann SR. A role for transcriptional repression of p21CIP1 by c-Myc in overcoming transforming growth factor $\beta$-induced cell-cycle arrest. Proc Natl Acad Sci U S A. 2000; 97:9498-503.

39. Gartel AL, Ye X, Goufman E, Shianov P, Hay N, Najmabadi F, Tyner AL. Myc represses the p21(WAF1/CIP1) promoter and interacts with $\mathrm{Sp} 1 / \mathrm{Sp} 3$. Proc Natl Acad Sci U S A. 2001; 98:4510-15.

40. Mitchell KO, El-Deiry WS. Overexpression of c-Myc inhibits p21WAF1/CIP1 expression and induces S-phase entry in 12-O-tetradecanoylphorbol-13-acetate (TPA)sensitive human cancer cells. Cell Growth Differ. 1999; 10:223-30.

41. Seoane J, Le HV, Massague J. Myc suppression of the p21(Cip1) Cdk inhibitor influences the outcome of the p53 response to DNA damage. Nature 2002; 419:729-34.

42. Wu S, Cetinkaya C, Munoz-Alonso MJ, Von der Lehr N, Bahram F, Beuger V, Eilers M, Leon J, Larsson LG. Myc represses differentiation-induced $\mathrm{p} 21 \mathrm{CIP} 1$ expression via Miz-1-dependent interaction with the p21 core promoter. Oncogene. 2003; 22:351-60.

43. Cho JG, Park S, Lim CH, Kim HS, Song SY, Roh TY, Sung JH, Suh W, Ham SJ, Lim KH, Park SG. ZNF224, Krüppel 
like zinc finger protein, induces cell growth and apoptosisresistance by down-regulation of $\mathrm{p} 21$ and $\mathrm{p} 53$ via miR-663. Oncotarget. 2016; 7:31177-90. https://doi.org/10.18632/ oncotarget.8870.

44. Yang Y, Li-Li W, Heng-Xiang W, Zi-Kuan G, Xiao-Fang G, Jian C, Yong-Hui L, Li-Ping D, Li Y. The epigeneticallyregulated miR-663 targets H-ras in K-562 cells. The Febs Journal. 2013; 20:5109-17.

45. Satoki N, Daisuke Y, Lin T, Yasuyuki N, Tomonari T, Isao H, Kazuyuki S, Kiyoshi S, Shinya F, Kazunori O. Downregulation of Thanatos-associated protein 11 by BCR-ABL promotes CML cell proliferation through c-Myc expression. Int J Cancer. 2012; 130:1046-59.

46. Romano S, Xiao Y, Nakaya M, D’Angelillo A, Chang M, Jin J. FKBP51 employs both scaffold and isomerase functions to promote NF- $\kappa \mathrm{B}$ activation in melanoma. Nucleic Acids Res. 2015; 43:6983-93.

47. Medugno L, Costanzo P, Lupo A, Monti M, Florio F, Pucci P, Izzo P. A novel zinc nger transcriptional repressor, ZNF224, interacts with the negative regulatory element
(AldA-NRE) and inhibits gene expression. FEBS Letters. 2003; 534:93-100.

48. He TC, Sparks AB, Rago C, Hermeking H, Zawel L, da Costa LT, Morin PJ, Vogelstein B, Kinzler KW. Identification of c-Myc as a target of the APC pathway. Science. 1998; 281:1509-12.

49. Cesaro E, De Cegli R, Medugno L, Florio F, Grosso M, Lupo A, Izzo P, Costanzo P. The Kruppel-like zinc finger protein ZNF224 recruits the arginine methyltransferase PRMT5 on the transcriptional repressor complex of the aldolase A gene. J Biol Chem. 2009; 284:32321-30.

50. Herrant $M$, Jacquel A, Marchetti S, Belhacène $N$, Colosetti $P$, Luciano F, Auberger P. Cleavage of Mcl-1 by caspases impaired its ability to counteract Bim-induced apoptosis. Oncogene. 2004; 23:7863-73. 